\title{
Biological Clocks: Nature, Organization and Interactions
}

\author{
Nicolas Wiernsperger ${ }^{\mathrm{a}, \mathrm{b}, \mathrm{d}}$ Jean Robert Rapin ${ }^{\mathrm{b}, \mathrm{c}}$
}

\begin{abstract}
Probably few domains of medical research have experienced so much interest within such short time frame as the identification and functioning of biological clocks. While circadian clocks are the best-known, very recent research has shown that biological clocks are numerous, closely interacting and, very importantly, that some are conserved from primitive organisms. While the central coordinator is located in the suprachiasmatic nucleus and mainly sensitive to light/darkness, also multiple peripheral clocks exist, which are sensitive to food and local metabolism and involved in both metabolism and vascular physiology work. The whole system works in a remarkably coordinated manner, although peripheral clocks can also work independently from the central clock. It can be seen how hormonal profiles vary physiologically over a 24h period and how disturbances in these processes can deregulate the system and the metabolic homeostasis. Many genes have just been identified, which largely help to understand functioning of the system and how de-synchronization (due in particular to modern lifestyle) can easily perturb it. The fact that essentially all factors known to be causally involved in the cardiometabolic syndrome (insulin resistance, vascular dysfunction) are involved strongly supports the key role clocks and their dysfunction may play in the present worldwide burden of this pathology. In particular it is impressive to note that simply changes in clock synchronization can induce these disorders, without necessarily invoking overeating and/or sedentarity usually considered as culprits.
\end{abstract}

Manuscript accepted for publication Sept 26, 2011

${ }^{a}$ CaRmen Laboratory, INSERM U1060, INSA Lyon, Bld Jean Capelle, F-69621 Villeurbanne, France

${ }^{\mathrm{b}}$ REMEDES, 920 route du Paradis, F-69530 Orlienas, France

${ }^{\mathrm{c}}$ Faculty of Medicine and Pharmacy, University of Burgundy, 3 Bld

Jeanne d'Arc, F-21000 Dijon, France

${ }^{\mathrm{d} C}$ Corresponding author: Nicolas Wiernsperger.

Email: nicolas.wiernsperger@free.fr

doi:10.4021/jem44w
Keywords: Metabolic syndrome; Circadian; Biological clock; Gene; Hormones

\section{Introduction}

The worldwide, ongoing burden of cardiometabolic syndrome and diabetes is generally attributed to major changes in lifestyle, more particularly wrong alimentary habits (overeating) and sedentarity. It is noticeable that the latter are directly linked to major social and technological modifications during the last 4 or 5 decades, more particularly increases in leisure time and availability of electricity. Thereby whole populations progressively changed their daily living habits, for example a shift in their sleep/wakefulness rhythms by several hours, having dinner at later times and going to bed much later than their ancestors.

Is it a hazard that the dysmetabolic burden goes in parallel with these changes in biological rhythms? Certainly not! Mal- or non-adaptation of our numerous organ and cell clock genes to these new ways of life may therefore be directly involved in the development of the metabolic diseases.

At least two major observations support this concept: first, the health problems expressed by shift workers both in metabolic [1, 2] and cardiovascular aspects [3, 4]. Second, sleep disturbances of various nature (duration, shifting, interruptions) have recently been demonstrated to be causally linked to metabolic disorders [5, 6]. These pathological changes are found in many other pathologies associated with modifications in biological rhythms, as will be seen.

Few domains have experienced such an abrupt increase in knowledge within so short time as the medical comprehension of the consequences of whole organ or cellular rhythm dysregulations. It is therefore the aim of this review to expose to physicians: a) the nature and pathophysiological background of various rhythms and their interactions and b) their implication in cardiometabolic diseases and the potential consequences on alimentary habits. The aim of this review is not to go into a detailed description of all their characteristics but mainly to make physicians aware of the 
Table 1. Some Selected Parameters of the Cardiometabolic Syndrome With Demonstrated Circadian Variation

\begin{tabular}{ll}
\hline No. & Selected parameters \\
\hline 1 & GLYCAEMIA \\
2 & GLUCOSE UPTAKE \\
3 & GLUCOSE TOLERANCE \\
4 & INSULINAEMIA \\
5 & CORTISOL \\
6 & CORTISOL-RELATED GENES \\
7 & LEPTIN \\
8 & ADIPONECTIN \\
9 & MELATONIN \\
10 & NOCTURNIN \\
11 & CYTOKINES \\
12 & LIPOPROTEIN LIPASE \\
13 & LIPID SYNTHESIS \\
14 & GASTRIC EMPTYING \\
15 & HEPATIC GLUCONEOGENESIS \\
16 & HDL / LDL \\
17 & PAI-1 \\
18 & FIBRINOGEN \\
19 & NITRIC OXIDE \\
20 & PEROXIREDOXINS \\
21 & IMMUNE FACTORS \\
\hline
\end{tabular}

importance of these hitherto unrecognized parameters in metabolic disorders. Consequently the reader will regularly be referred to recent, excellent reviews dealing with the specific aspects of this very evolving topic.

\section{Metabolic Homeostasis: a "Symphonic Or- chestra"}

Metabolic variations and their physiological regulation might be compared to a symphonic orchestra. A symphonic piece sounds great provided all groups of instrumentalists play exactly at the time they have to play, both within their instrument group and between the groups. However the groups play different rhythms at different moments. Any error in timing leads invariably to dysharmony, the reason why all these various rhythms must be controlled in a highly coordinated fashion by a "supervisor" which is the orchestra conductor. As will be seen this is exactly what occurs when we consider biological rhythms in peripheral tissues and their control by the central nervous system. Like in music, shifts in biological rhythm synchronization result in dysharmony with direct consequences on health.

\section{Multiplicity of biological rhythms}

Various biological rhythms can be observed, ranging from long-term (seasonal, for example), mid-term (circadian, i.e. over $24 \mathrm{~h}$ ) to very short cycle lengths. However even within the circadian period, subdivisions must be made because of so-called ultradian rhythms. The latter can be of low (period of several minutes) or high frequency (period of $1-10 \mathrm{~Hz}$ ). Suffice to mention here that in fact most variables involved in metabolic homeostasis demonstrate rhythmicity (Table 1). To work properly, this requires a synchronized control, which is located in the hypothalamus, more exactly in the suprachiasmatic nucleus (SCN), where even individual neurones function as oscillators $[7,8]$. Specific clock genes are presently under intense investigation, details of which can be found in dedicated reviews [7, 9]. The best known genes are termed CLOCK, BMal1, PER 1-3 and Cryptochrome 1 and 2. It is assumed that up to $10 \%$ of genes are clock-controlled.

Most organisms function with a circadian timing system to cope with and anticipate changes in seasonal and daily rhythms. The identification of "clock genes" is little older than a decade and helped greatly understanding and discriminating the role of the two main control systems of circadian rhythms: the SCN-dependent and the SCN-independent rhythms. While the first is essentially light/darkness-regulated, the second are "food entrainable" and known as "food entrainable oscillators", which require physiological cues to maintain their rhythms [10]. Details about functioning and underlying mechanisms can be found in very recent reviews [11]. Indeed the fact that the SNC controls the timely ad- 
equacy of metabolic rhythms does not exclude the existence of partly fully autonomic clocks in various peripheral tissues such as liver, pancreas or blood vessels [10-13]. Interestingly circadian rhythms seem to be partly highly conserved mechanisms since they have been described in primitive organisms such as the primitive nematode C. elegans [14]. Impressively it was reported very recently that even non-nucleated cells such as erythrocytes exhibit rhythmic variations in the antioxidant peroxiredoxins, with direct consequences on blood oxygenation [15].

Rhythmic metabolic variations: focus on some main players in metabolic homeostasis

Peripheral tissues exhibit rhythmic behaviours which can be controlled by central (nervous) or local (metabolic, hormonal) factors as well as by intrinsic rhythm-generating pacemakers. While it appears logical that substances produced by the biochemical machinery in the immediate vicinity of cells may directly induce metabolic variations, intrinsic rhythmicity (oscillators) is poorly understood. Indeed the latter can even be observed for periods of hours or days in pancreatic islets [16] or adipocytes kept under ex-vivo conditions [17] as well as in cultured skeletal muscle cells [18].

In rodents locomotor activity increases before the time of food presentation, the so-called food anticipatory activity. This behaviour is considered to be completely independent of the SCN [19, 20]. In humans, such an effect is seen in hormonal secretion in people having regular meal times: it is the "cephalic phase" of insulin secretion, which occurs upon the visual and/or olfactive stimulus of food presentation preceding food ingestion. This physiological phenomenon is very important for coordinated digestion and partly determines postprandial glycemic regulation [21]. The small, early increase in plasma insulin may open the nutritive capillary bed in target tissues such as skeletal muscle to store glucose from the meal [22]. It has been shown that the cephalic phase is a conditioned process [23] and its dysregulation is conceivably a possible cause of impaired postprandial glucose tolerance.

Insulin and glucose exhibit oscillating values in plasma over the day [24, 25]. Insulin is delivered into the portal vein in a pulsatile manner, with pulse intervals of 5-15 minutes [24, 26-28], which regulate hepatic hormone extraction and thereby its peripheral delivery [29]. A much slower (ultradian) oscillation for insulin has also been discovered [30]. Interestingly, insulin rhythms persist even during prolonged fasting, i.e. when glucose levels are low [31]. Precise mechanisms regulating insulin oscillations are still under investigation [32]. The pancreas is equipped with intrinsic pacemakers which are nevertheless under neural central modulation. Experiments revealed that lack of clock function in pancreas of mutant mice resulted in severe glucose intolerance and defective insulin production, strengthening the importance of this intrinsic circadian clock for normal glucose homeo- stasis [14]. In diabetes [33], but also in diabetic relatives [34], pulsatile insulin secretion is impaired. A main finding is that glucose tolerance, mainly due to variations in insulin sensitivity, also varies during the 24h in normal individuals, showing reduction in the evening and early night [35], while this is not observed in obese [36] and in diabetic patients [13]. Thus, although the circadian variations are small, they appear to be physiologically important and are worth larger investigations.

The liver plays a most prominent role in glycemic regulation: it is shown that deletion of BMal1 in mice leads to various defaults in glucose homeostasis [37]. In fact both glucose tolerance and insulin sensitivity exhibit daily rhythms [38]. Disruption of clock genes in the liver and skeletal muscle of mice leads to impaired glucose tolerance and some contradictory effects on insulin sensitivity [39]. Others have reported obesity, hyperleptinemia, hyperglycemia and hepatic steatosis in this model [40]. In humans polymorphisms of the Clock gene are associated with obesity and metabolic syndrome [41]. Hyperglycemia has also been associated with variants of the circadian gene Per2 [42].

Fat cells are recognized as playing a cardinal role in the metabolic syndrome. Disruption in sleep patterns are associated with increased body fat [43] and it suggested that molecular clocks at the level of adipocytes are disturbed in such situations [44]. Conversely obesity alters circadian clock gene expression [45].

These data suggest that rhythmicity and metabolic disorders are linked in a bidirectional fashion [46]. The same phenomenon is known to occur among sleep disorders and cardiometabolic parameters [47, 48]. Here too it was shown that a shift in sleep (day sleep) increased IGFBP1 and elevated cortisol as compared with normal nocturnal sleep [49]. This important aspect was recently reviewed [50].

\section{Rhythmic cardiovascular variations}

Rhythmic variability is well-known in cardiovascular physiology [51]; it represents an interesting aspect if we recall the close link between metabolic disorders and cardiovascular events, leading to the cardiometabolic syndrome. One of the best known characteristic of pathological chronobiology in current medicine is the preferential occurrence of heart infarction in morning hours. The observation that most cardiovascular physiological parameters (blood pressure, heart rate) exhibit circadian behaviour has led to the recent notion of chronocardiology [52]. Vascular diameter and vessel reactivity show diurnal variation [53]. Tissue oxygen tension, reflecting microvascular blood perfusion, shows a typical oscillatory behaviour in the brain [54]. Platelet aggregation and PAI-1 levels, both key factors in hemostasis, peak at awakening times $[55,56]$. Such aspects (should) have a direct impact on therapeutic protocols (chronotherapy) [57-59].

Nutrient delivery is finely regulated by the microvascular 
flow changes, allowing to constantly and precisely adapt perfusion to local needs or, in case of glucose homeostasis, to store glucose in skeletal muscles during postprandial periods. This regulation involves a phenomenon known as precapillary vasomotion, an observable alternance of diameter changes in small terminal arterioles, which open or close individual capillary units [60].

\section{Some examples of biological rhythm disorders in cardio- metabolic regulation}

One of the most prominent aspects of biological rhythms is evidently the day/night cycle. As stated before, a large amount of evidence for its importance comes from observations in shift workers and subjects suffering sleep disorders. The past years have increasingly demonstrated how sleep disorders are bidirectionaly linked to the metabolic syndrome and to vascular derangements [6, 22, 61]. In this context, melatonin seems a good candidate to illustrate how modifications in life style can impact our health. Although melatonin is best known as the "sleeping hormone", only recent discoveries showed its crucial importance in both metabolic and cardiovascular physiology. Melatonin is involved in the synchronization of various organs involved in glycemic regulation and insulin secretion [62]. Absence of melatonin leads to night-time hepatic insulin resistance and increased gluconeogenesis [63]. The night/day differences observed in normal physiology are lost in metabolic syndrome patients and are negatively linked to fasting plasma glucose [64]. Melatonin receptors are expressed in pancreatic islets [65] and absence of melatonin-1 receptors in mice results in insulin resistance [66]. Circadian insulin secretion is related to melatonin variations and it is shown that polymorphisms of the melatonin-2 receptor in humans are linked to elevated risks for type 2 diabetes [67]. Conversely melatonin (or agonist) administration prevents diet-induced obesity in rats $[68,69]$.Very interestingly, melatonin is also involved in cardiovascular functions [70] and melatonin receptors are found in cardiomyocytes [71]. Here again, melatonin treatment of obese rats improves cardiac postischemic injury [68]. Therefore melatonin appears as an attractive target for preventing or improving diabetes.

Although information in the vascular field is still limited, it was shown that mice bearing mutations in clock genes such as Bmal-1, Clock or Per2 exhibited defective vascular remodelling and endothelial dysfunction in larger vessels $[71,72]$. In humans hypertension in metabolic syndrome is associated with variants of the Npas2 gene [42].

In the microcirculation, vasomotion can be measured with a periodicity of $1-10 \mathrm{~Hz}$ under basal conditions but can be activated by physiological changes such as postprandial substrate delivery, when insulin promotes glucose uptake and storage in skeletal muscle [73]. Synchronization between communicating cells in the arteriolar wall is the prerequisite for this regulatory mechanism to function. Mechanisms to explain it are still under exploration [60]. We and others have suggested, and partly demonstrated, that defective arteriolar vasomotion (=absence of synchronization in oscillator activity) is linked to insulin resistance and defective glucose uptake [22, 73]. Finally the circadian clock also regulates triglyceride metabolism within cardiomyocytes, as shown by metabolic defects in hearts of clock-mutant mice [74]. In humans, visceral fat accumulation, characterizing the metabolic syndrome, was recently reported to correlate with defects in circadian blood pressure [75]. These yet limited data nevertheless strongly support an implication of rhythmic disorders in vascular physiology. Interested readers will find more information in excellent recent reviews [8, 75].

As seen, modifications in clock genes and living behaviour lead to changes characteristic of metabolic syndrome: insulin resistance, obesity, dyslipidemia, cardiovascular disturbances.

\section{Conclusion}

Similarly to a symphony orchestra, where small groups cope with their individual rhythm but in a globally coordinated fashion, mechanisms regulating metabolic homeostasis require that the whole operates in phase and be controlled for a synchronous and harmonious functioning. Failure to work in a finely synchronized manner, at very precise timings, leads to pathological modifications in metabolic homeostasis [46, 76-80].

Misalignment of daily-life behaviour and stable circadian oscillators leads to adverse cardiometabolic effects [81]. While these data suggest that troubles in circadian rhythms are largely acquired because of inadequate life-style, it can also be inherited: adult metabolic diseases are known to originate for a great part from so-called fetal programming; in mice it was shown that protein malnutrition during pregnancy resulted in altered circadian rhythms before obesity developed [82].

It is fascinating to see that a metabolic syndrome might be partially or fully induced just by changing some of our cellular rhythms without invoking alimentary misbehaviours or lack of exercise. Considering what has been discovered during the recent 5 years, such completely new approaches may well explain a good part of the burden of metabolic diseases encountered worldwide. Clearly all main players of the metabolic syndrome (insulin secretion/sensitivity, glycemia, lipid metabolism, hepatic regulation of glycemia, cortisol, adipokines) display cyclic variations during or overt the day. The same seems to hold true for factors responsible fort he cardiovascular disturbances typically linked to the metabolic disorders (Table 1).

It will also be interesting to learn from these observations, to identify possible errors in our eating habits accord- 
ing to daily lifestyle changes and to imagine how we might correct these to take into account the limited flexibility of our clock genes.

\section{References}

1. Esquirol Y, Bongard V, Mabile L, Jonnier B, Soulat JM, Perret B. Shift work and metabolic syndrome: respective impacts of job strain, physical activity, and dietary rhythms. Chronobiol Int. 2009;26(3):544-559.

2. Suwazono Y, Dochi M, Oishi M, Tanaka K, Kobayashi E, Sakata K. Shiftwork and impaired glucose metabolism: a 14-year cohort study on 7104 male workers. Chronobiol Int. 2009;26(5):926-941.

3. Leclerc A. Shift-work and cardiovascular disease. Eur J Epidemiol. 2010;25(5):285-286.

4. Szosland D. Shift work and metabolic syndrome, diabetes mellitus and ischaemic heart disease. Int J Occup Med Environ Health. 2010;23(3):287-291.

5. Donga E, van Dijk M, van Dijk JG, Biermasz NR, Lammers GJ, van Kralingen KW, Corssmit EP, et al. A single night of partial sleep deprivation induces insulin resistance in multiple metabolic pathways in healthy subjects. J Clin Endocrinol Metab. 2010;95(6):2963-2968.

6. Morselli L, Leproult R, Balbo M, Spiegel K. Role of sleep duration in the regulation of glucose metabolism and appetite. Best Pract Res Clin Endocrinol Metab. 2010;24(5):687-702.

7. Froy O. The circadian clock and metabolism. Clin Sci (Lond). 2011;120(2):65-72.

8. Garaulet M, Ordovas JM, Madrid JA. The chronobiology, etiology and pathophysiology of obesity. Int J Obes (Lond). 2010;34(12):1667-1683.

9. Gallou-Kabani C, Vige A, Junien C. Lifelong circadian and epigenetic drifts in metabolic syndrome. Epigenetics. 2007;2(3):137-146.

10. Dibner C, Schibler U, Albrecht U. The mammalian circadian timing system: organization and coordination of central and peripheral clocks. Annu Rev Physiol. 2010;72:517-549.

11. Shibata S, Tahara Y, Hirao A. The adjustment and manipulation of biological rhythms by light, nutrition, and abused drugs. Adv Drug Deliv Rev. 2010;62(9-10):918927.

12. Gimble JM, Floyd ZE. Fat circadian biology. J Appl Physiol. 2009;107(5):1629-1637.

13. Sturis J, O’Meara NM, Shapiro ET, Blackman JD, Tillil H, Polonsky KS, Van Cauter E. Differential effects of glucose stimulation upon rapid pulses and ultradian oscillations of insulin secretion. J Clin Endocrinol Metab. 1993;76(4):895-901.

14. Migliori ML, Simonetta SH, Romanowski A, Golombek DA. Circadian rhythms in metabolic variables in Cae- norhabditis elegans. Physiol Behav. 2011;103(3-4):315320.

15. O’Neill JS, Reddy AB. Circadian clocks in human red blood cells. Nature. 2011;469(7331):498-503.

16. Sadacca LA, Lamia KA, deLemos AS, Blum B, Weitz CJ. An intrinsic circadian clock of the pancreas is required for normal insulin release and glucose homeostasis in mice. Diabetologia. 2011;54(1):120-124.

17. Gomez-Santos C, Gomez-Abellan P, Madrid JA, Hernandez-Morante JJ, Lujan JA, Ordovas JM, Garaulet M. Circadian rhythm of clock genes in human adipose explants. Obesity (Silver Spring). 2009;17(8):1481-1485.

18. Feneberg R, Lemmer B. Circadian rhythm of glucose uptake in cultures of skeletal muscle cells and adipocytes in Wistar-Kyoto, Wistar, Goto-Kakizaki, and spontaneously hypertensive rats. Chronobiol Int. 2004;21(45):521-538.

19. Mistlberger RE. Food-anticipatory circadian rhythms: concepts and methods. Eur J Neurosci. 2009;30(9):17181729.

20. Storch KF, Weitz CJ. Daily rhythms of food-anticipatory behavioral activity do not require the known circadian clock. Proc Natl Acad Sci U S A. 2009;106(16):68086813.

21. Teff KL. How neural mediation of anticipatory and compensatory insulin release helps us tolerate food. Physiol Behav. 2011;103(1):44-50.

22. Wiernsperger N, Nivoit P, De Aguiar LG, Bouskela E. Microcirculation and the metabolic syndrome. Microcirculation. 2007;14(4-5):403-438.

23. Woods SC, Vasselli JR, Kaestner E, Szakmary GA, Milburn P, Vitiello MV. Conditioned insulin secretion and meal feeding in rats. J Comp Physiol Psychol. 1977;91(1):128-133.

24. Lang DA, Matthews DR, Peto J, Turner RC. Cyclic oscillations of basal plasma glucose and insulin concentrations in human beings. $\mathrm{N}$ Engl J Med. 1979;301(19):1023-1027.

25. Mejean L, Bicakova-Rocher A, Kolopp M, Villaume C, Levi F, Debry G, Reinberg A, et al. Circadian and ultradian rhythms in blood glucose and plasma insulin of healthy adults. Chronobiol Int. 1988;5(3):227-236.

26. Levy JC. Insulin signalling through ultradian oscillations. Growth Horm IGF Res. 2001;11 Suppl A:S17-23.

27. Pedersen MG, Bertram R, Sherman A. Intra- and interislet synchronization of metabolically driven insulin secretion. Biophys J. 2005;89(1):107-119.

28. Song SH, McIntyre SS, Shah H, Veldhuis JD, Hayes PC, Butler PC. Direct measurement of pulsatile insulin secretion from the portal vein in human subjects. J Clin Endocrinol Metab. 2000;85(12):4491-4499.

29. Meier JJ, Veldhuis JD, Butler PC. Pulsatile insulin secretion dictates systemic insulin delivery by regulating hepatic insulin extraction in humans. Diabetes. 
2005;54(6):1649-1656.

30. Schmitz O, Rungby J, Edge L, Juhl CB. On high-frequency insulin oscillations. Ageing Res Rev. 2008;7(4):301305.

31. Merl V, Peters A, Oltmanns KM, Kern W, Hubold C, Hallschmid M, Born J, et al. Preserved circadian rhythm of serum insulin concentration at low plasma glucose during fasting in lean and overweight humans. Metabolism. 2004;53(11):1449-1453.

32. Tengholm A, Gylfe E. Oscillatory control of insulin secretion. Mol Cell Endocrinol. 2009;297(1-2):58-72.

33. Porksen N, Hollingdal M, Juhl C, Butler P, Veldhuis JD, Schmitz O. Pulsatile insulin secretion: detection, regulation, and role in diabetes. Diabetes. 2002;51 Suppl 1:S245-254.

34. O’Rahilly S, Turner RC, Matthews DR. Impaired pulsatile secretion of insulin in relatives of patients with non-insulin-dependent diabetes. N Engl J Med. 1988;318(19):1225-1230.

35. la Fleur SE, Kalsbeek A, Wortel J, Fekkes ML, Buijs RM. A daily rhythm in glucose tolerance: a role for the suprachiasmatic nucleus. Diabetes. 2001;50(6):12371243.

36. Lee A, Ader M, Bray GA, Bergman RN. Diurnal variation in glucose tolerance. Cyclic suppression of insulin action and insulin secretion in normal-weight, but not obese, subjects. Diabetes. 1992;41(6):750-759.

37. Lamia KA, Storch KF, Weitz CJ. Physiological significance of a peripheral tissue circadian clock. Proc Natl Acad Sci U S A. 2008;105(39):15172-15177.

38. Kalsbeek A, Yi CX, La Fleur SE, Fliers E. The hypothalamic clock and its control of glucose homeostasis. Trends Endocrinol Metab. 2010;21(7):402-410.

39. Kennaway DJ, Owens JA, Voultsios A, Boden MJ, Varcoe TJ. Metabolic homeostasis in mice with disrupted Clock gene expression in peripheral tissues. Am J Physiol Regul Integr Comp Physiol. 2007;293(4):R15281537.

40. Turek FW, Joshu C, Kohsaka A, Lin E, Ivanova G, McDearmon E, Laposky A, et al. Obesity and metabolic syndrome in circadian Clock mutant mice. Science. 2005;308(5724):1043-1045.

41. Scott EM, Carter AM, Grant PJ. Association between polymorphisms in the Clock gene, obesity and the metabolic syndrome in man. Int $\mathrm{J}$ Obes (Lond). 2008;32(4):658-662.

42. Englund A, Kovanen L, Saarikoski ST, Haukka J, Reunanen A, Aromaa A, Lonnqvist J, et al. NPAS2 and PER2 are linked to risk factors of the metabolic syndrome. J Circadian Rhythms. 2009;7:5.

43. Broussard J, Brady MJ. The impact of sleep disturbances on adipocyte function and lipid metabolism. Best Pract Res Clin Endocrinol Metab. 2010;24(5):763-773.

44. Bray MS, Tsai JY, Villegas-Montoya C, Boland BB,
Blasier Z, Egbejimi O, Kueht M, et al. Time-of-daydependent dietary fat consumption influences multiple cardiometabolic syndrome parameters in mice. Int $\mathrm{J}$ Obes (Lond). 2010;34(11):1589-1598.

45. Green CB, Takahashi JS, Bass J. The meter of metabolism. Cell. 2008;134(5):728-742.

46. Kaneko K, Yamada T, Tsukita S, Takahashi K, Ishigaki Y, Oka Y, Katagiri H. Obesity alters circadian expressions of molecular clock genes in the brainstem. Brain Res. 2009;1263:58-68.

47. Wiernsperger N, Nivoit P, Bouskela E. Obstructive sleep apnea and insulin resistance: a role for microcirculation? Clinics (Sao Paulo). 2006;61(3):253-266.

48. Chaput JP, Despres JP, Bouchard C, Astrup A, Tremblay A. Sleep duration as a risk factor for the development of type 2 diabetes or impaired glucose tolerance: analyses of the Quebec Family Study. Sleep Med. 2009;10(8):919924.

49. Rehman JU, Brismar K, Holmback U, Akerstedt T, Axelsson J. Sleeping during the day: effects on the 24-h patterns of IGF-binding protein 1, insulin, glucose, cortisol, and growth hormone. Eur J Endocrinol. 2010;163(3):383-390.

50. Eckel-Mahan K, Sassone-Corsi P. Metabolism control by the circadian clock and vice versa. Nat Struct Mol Biol. 2009;16(5):462-467.

51. Keaney JF, Jr., Weaver DR. Vascular rhythms and adaptation: do your arteries know what time it is? Circulation. 2009;119(11):1463-1466.

52. Guo YF, Stein PK. Circadian rhythm in the cardiovascular system: chronocardiology. Am Heart J. 2003;145(5):779-786.

53. Bau PF, Bau CH, Naujorks AA, Rosito GA, Fuchs FD. Diurnal variation of vascular diameter and reactivity in healthy young men. Braz J Med Biol Res. 2008;41(6):500-503.

54. Obrig H, Neufang M, Wenzel R, Kohl M, Steinbrink J, Einhaupl K, Villringer A. Spontaneous low frequency oscillations of cerebral hemodynamics and metabolism in human adults. Neuroimage. 2000;12(6):623-639.

55. Cooke-Ariel H. Circadian variations in cardiovascular function and their relation to the occurrence and timing of cardiac events. Am J Health Syst Pharm. 1998;55 Suppl 3:S5-11.

56. Montagnana M, Salvagno GL, Lippi G. Circadian variation within hemostasis: an underrecognized link between biology and disease? Semin Thromb Hemost. 2009;35(1):23-33.

57. Mandal AS, Biswas N, Karim KM, Guha A, Chatterjee S, Behera M, Kuotsu K. Drug delivery system based on chronobiology--A review. J Control Release. 2010;147(3):314-325.

58. Haus E. Chronobiology of hemostasis and inferences for the chronotherapy of coagulation disorders and 
thrombosis prevention. Adv Drug Deliv Rev. 2007;59(910):966-984.

59. Takeda N, Maemura K. Cardiovascular disease, chronopharmacotherapy, and the molecular clock. Adv Drug Deliv Rev. 2010;62(9-10):956-966.

60. Aalkjaer C, Boedtkjer D, Matchkov V. Vasomotion - what is currently thought? Acta Physiol (Oxf). 2011;202(3):253-269.

61. Spiegel K. Sleep loss as a risk factor for obesity and diabetes. Int J Pediatr Obes. 2008;3 Suppl 2:27-28.

62. Muhlbauer E, Gross E, Labucay K, Wolgast S, Peschke E. Loss of melatonin signalling and its impact on circadian rhythms in mouse organs regulating blood glucose. Eur J Pharmacol. 2009;606(1-3):61-71.

63. Nogueira TC, Lellis-Santos C, Jesus DS, Taneda M, Rodrigues SC, Amaral FG, Lopes AM, et al. Absence of melatonin induces night-time hepatic insulin resistance and increased gluconeogenesis due to stimulation of nocturnal unfolded protein response. Endocrinology. 2011;152(4):1253-1263.

64. Robeva R, Kirilov G, Tomova A, Kumanov P. Melatonin-insulin interactions in patients with metabolic syndrome. J Pineal Res. 2008;44(1):52-56.

65. Mulder H, Nagorny CL, Lyssenko V, Groop L. Melatonin receptors in pancreatic islets: good morning to a novel type 2 diabetes gene. Diabetologia. 2009;52(7):12401249.

66. Contreras-Alcantara S, Baba K, Tosini G. Removal of melatonin receptor type 1 induces insulin resistance in the mouse. Obesity (Silver Spring). 2010;18(9):18611863.

67. Peschke E, Muhlbauer E. New evidence for a role of melatonin in glucose regulation. Best Pract Res Clin Endocrinol Metab. 2010;24(5):829-841.

68. Nduhirabandi F, Du Toit EF, Blackhurst D, Marais D, Lochner A. Chronic melatonin consumption prevents obesity-related metabolic abnormalities and protects the heart against myocardial ischemia and reperfusion injury in a prediabetic model of diet-induced obesity. J Pineal Res. 2011;50(2):171-182.

69. She M, Deng X, Guo Z, Laudon M, Hu Z, Liao D, Hu $\mathrm{X}$, et al. NEU-P11, a novel melatonin agonist, inhibits weight gain and improves insulin sensitivity in high-fat/ high-sucrose-fed rats. Pharmacol Res. 2009;59(4):248253.

70. Dominguez-Rodriguez A, Abreu-Gonzalez P, SanchezSanchez JJ, Kaski JC, Reiter RJ. Melatonin and circa- dian biology in human cardiovascular disease. J Pineal Res. 2010;49(1):14-22.

71. Peliciari-Garcia RA, Zanquetta MM, Andrade-Silva J, Gomes DA, Barreto-Chaves ML, Cipolla-Neto J. Expression of circadian clock and melatonin receptors within cultured rat cardiomyocytes. Chronobiol Int. 2011;28(1):21-30.

72. Viswambharan H, Carvas JM, Antic V, Marecic A, Jud C, Zaugg CE, Ming XF, et al. Mutation of the circadian clock gene Per2 alters vascular endothelial function. Circulation. 2007;115(16):2188-2195.

73. Renaudin C, Michoud E, Rapin JR, Lagarde M, Wiernsperger N. Hyperglycaemia modifies the reaction of microvessels to insulin in rat skeletal muscle. Diabetologia. 1998;41(1):26-33.

74. Tsai JY, Kienesberger PC, Pulinilkunnil T, Sailors MH, Durgan DJ, Villegas-Montoya C, Jahoor A, et al. Direct regulation of myocardial triglyceride metabolism by the cardiomyocyte circadian clock. J Biol Chem. 2010;285(5):2918-2929.

75. Laposky AD, Bass J, Kohsaka A, Turek FW. Sleep and circadian rhythms: key components in the regulation of energy metabolism. FEBS Lett. 2008;582(1):142-151.

76. Maury E, Ramsey KM, Bass J. Circadian rhythms and metabolic syndrome: from experimental genetics to human disease. Circ Res. 2010;106(3):447-462.

77. Arble DM, Bass J, Laposky AD, Vitaterna MH, Turek FW. Circadian timing of food intake contributes to weight gain. Obesity (Silver Spring). 2009;17(11):21002102.

78. Bechtold DA, Gibbs JE, Loudon AS. Circadian dysfunction in disease. Trends Pharmacol Sci. 2010;31(5):191198.

79. Hastings MH, Reddy AB, Maywood ES. A clockwork web: circadian timing in brain and periphery, in health and disease. Nat Rev Neurosci. 2003;4(8):649-661.

80. Zanquetta MM, Correa-Giannella ML, Monteiro MB, Villares SM. Body weight, metabolism and clock genes. Diabetol Metab Syndr. 2010;2(53.

81. Scheer FA, Hilton MF, Mantzoros CS, Shea SA. Adverse metabolic and cardiovascular consequences of circadian misalignment. Proc Natl Acad Sci U S A. 2009;106(11):4453-4458.

82. Sutton GM, Centanni AV, Butler AA. Protein malnutrition during pregnancy in C57BL/6J mice results in offspring with altered circadian physiology before obesity. Endocrinology. 2010;151(4):1570-1580. 